\title{
Yersel Lazer Tarama Teknolojileriyle Oluşturulan 3B Modellerin Akıllı Kent Uygulamalarında Kullanımı: Mersin Süslü Çeşme Örneği
}

\author{
Doğa FIDAN $^{* 1}$ (i) , Şafak FİDAN 2 (b) \\ ${ }^{1}$ Konya Teknik Üniversitesi, Lisansüstü Eğitim Enstitüsü, Harita Mühendisliği Anabilim Dalı, Konya, Türkiye \\ ${ }_{2}^{2}$ Mersin Üniversitesi, Teknik Bilimler Meslek Yüksekokulu, Mimarlık ve Şehir Planlama Bölümü, Mersin, Türkiye
}

\author{
Anahtar Kelimeler \\ 3B Kent Modelleri, \\ Yersel Lazer Tarama, \\ Kent Bilgi Sistemleri, \\ Kentsel Yapilar, \\ 3B Modeller.
}

\begin{abstract}
öZ
Üç boyutlu (3B) akıllı kent modelleri, kentleri insanlara tanıtmanın etkili bir yoludur ve navigasyon, turizm, tanıtım, kent planlama, görselleştirme gibi pek çok farklı uygulamada yaygın olarak kullanılmaktadır. Ancak kentsel çevrelerdeki düzensiz kentsel yapılar ya da belirli insan dinamikleri gibi çeșitli etmenler nedeniyle 3B veriye erişim aşamasında bazı teknolojilerin kullanımı sınırlanabilir. Yersel lazer tarama (YLT) yöntemi kentlerin 3B modellenmesinde sağladığı kolaylıklar sayesinde sıklıkla kullanılan bir yöntemdir. $\mathrm{Bu}$ araştırma makalesi, kentlerin 3B sanal modellerinin üretilmesi için bir metodoloji önermektedir. Çalışmada, 3B kent uygulamalarında kullanılmak üzere bir yapının 3B modelini üretmek için, YLT teknolojilerinin kullanım olanaklarını araştırılmıştır. Çalıșma alanı Mersin'in tarihi çeşmelerinden biri olan Süslü Çeşme olarak belirlenmiştir. Çalışma kapsamında FARO marka FocusS 350 modelindeki YLT ile toplanan veri setleri SCENE yazılımında ișlenmiş ve 3B model üretimi bașarılı bir şekilde gerçekleștirilmiştir. Sonuç olarak, yüksek geometrik doğruluğa ve görsel bütünlüğe sahip bir 3B sanal model elde edilmiştir.
\end{abstract}

\section{The Use of 3D Models Created with Terrestrial Laser Scanning Technologies in Smart City Applications: The Example of Süslü Fountain in Mersin}

\author{
Keywords \\ 3D City Models, \\ Terrestrial Laser Scanning, \\ City İnformation Systems, \\ Urban Constructions, \\ 3D Models.
}

\begin{abstract}
Three-dimensional (3D) smart city models are an effective way of introducing cities to people and are widely used in many different applications such as navigation, tourism, publicity, urban planning and visualization. However, due to various factors such as irregular urban structures in urban environments or certain human dynamics, the use of some technologies may be limited in the stage of accessing 3D data. Terrestrial laser scanning (TLS) method has become a frequently used method thanks to the convenience it provides in 3D modeling of cities. This paper proposes a methodology for generating $3 \mathrm{D}$ virtual models of cities. In the study, the possibilities of using TLS technologies were investigated to produce a 3D model of a building to be used in 3D urban applications. The study area was determined as Süslü Fountain, the historical fountain of Mersin. Within the scope of the study, the data sets collected with TLS in the FARO brand FocusS 350 model were processed in SCENE software and 3D model production was successfully carried out. As a result, a 3D virtual model with high geometric accuracy and visual integrity was obtained.
\end{abstract}




\section{GİRiş}

Küresel kentleşme, günümüzde dünyanın en zorlu sorunlarından biri olmaya devam etmektedir. Kentlerdeki nüfusun giderek artması yerleşim merkezlerini birçok sorunla karşı karşıya getirmiştir. Bunların başında nüfus, trafikteki araç sayısının artması, son yıllarda yaşanan plansız kentleşmeler, buna paralel gerçekleşen kentsel dönüşüm, toplum güvenliği gibi sorunlar gelmekte ve kentlerin yönetimini giderek zorlamaktadır. Karmaşık yapılar olan kentlerin yönetiminde yenilikçi ve sürdürülebilir çözümlerin üretilmesi gereklidir (Yakar vd., 2009; Yakar vd., 2010; Su vd. 2011; Yılmaz vd., 2012; 2018).

Kolay erișilebilir, konum bilgisi sağlayan, halka açık ve gerçekçi akıllı kent modelleri bașta kamu kurumları olmak üzere birçok kullanıcı için önemli bir ihtiyaçtır (Polat 2020). Akıllı kent modellerinin oluşturulmasında farklı disiplinlerin beraber çalışmasıyla kentleri daha yaşanabilir hale getirmek ve sorunlar karşısında stratejik çözümler üretilebilecek altyapıyı oluşturmak olanaklıdır. Mevcut durumun değerlendirilmesi ve sürdürülebilir stratejilerin belirlenmesi kentlerin yönetiminde önemli bir yer tutmaktadır (Keleş \& Aydın 2020). Hızla gelișen teknoloji ve internetin yaygınlaşmasıyla beraber bilim insanları ve şirketler bu sorunları çözümlemek amacıyla akıllı kent modellerinin oluşturulması ve sunumu için çalışmalara başlamıştır. Bu kapsamda 3B sanal ve coğrafi modeller gibi yeni mekânsal bilgi teknolojileri ortaya çıkmış ve bu teknolojiler günümüzde de geliştirilmeye devam etmektedir (Yılmaz vd., 2008; Özerbil vd. 2014).

Akıllı kent kavramı, kentin yönetimi ve hizmet gibi alanlarda bilgi ve iletişim teknolojilerinin desteği ve vatandașların tam katılımı ile beraber teknolojilerin kente entegre edilmesini hedefleyen bir kavramdır. Ayrıca sınırlı kaynakların stratejik bir biçimde yönetilmesini sağlamaktadır. Diğer bir deyişle, kentin sürdürülebilir bir şekilde yönetilmesini tasarlayan, doğal kaynakların ve kentte sunulabilecek kamu hizmetlerinin tamamının katılımcı yönetişimle düzenlenmesini öngören bir teknolojidir (Aslan \& Bulut 2019).

Akıllı kent uygulamaları bugün; kentsel planlama, gerçek zamanlı haritalama ve simülasyonlar, kentsel planlama ve gelişim, kamu güvenliği ve şehir hizmetleri, yapılar ve afet yönetimi, lojistik, endüstriyel ve ticari faaliyetler, güvenlik, telekomünikasyon planlaması, acil durum ve müdahale planlamalarl, konum tabanl hizmetler ve emlak ve eğlence hizmetleri gibi kentsel alanda pek çok farklı alana katkı sağlamaktadır (Kostrikov 2019). Bu uygulamalar, kent sakinleri veya ziyaretçileri ile bilgi ve etkileşimini genişletmek için mükemmel araçlardır (Balsa-Barreiro \& Fritsch 2018). Ayrıca akıllı kent modelleri, kentlerin tarihi, mimari ve kültürel yönlerini de ortaya koyduğu için değerli bir araçtır. Bu nedenle yerel yönetimler kendi 3B akıllı kent modellerini oluşturma çalışmalarına başlamıştır (Yastıklı \& Çetin 2016; Şenol vd., 2021). Akıllı kent uygulamalarında, şehrin durumunu olabildiğince doğru bir şekilde ifade gereklidir. Kentin 3B modellemesi, kente akıllı çözümler gerektiren sorunların ilgili tüm yönlerini kapsamalıdır. $\mathrm{Bu}$ bağlamda 3B konumsal veriler, kent modelleri için kilit bir rol oynamaktadır (Jovanović 2020).
3B kent modelleme, son yllardaki teknolojik gelişmeler nedeniyle kolay bir süreç olarak kabul edilmektedir. Ancak, gerçek nesnelerin veya tüm dünyanın sayısal modelini oluşturma işlemi halen büyük bir çaba gerektirmektedir (Sahin vd. 2012). Bu kapsamda teknik altyapının oluşturulması ve iyileștirilmesi hususunda kente ait verilerin hızlı ve güvenli bir biçimde toplanması oldukça önemlidir. 3B kent modellerini üretebilmek için öncelikle modellenecek bölge ile ilgili çeşitli kaynaklardan 3B mekânsal verilerin toplanması gereklidir (Metin 2016; Ernst vd., 2021).

Verilerin hem toplanması hem de işlenmesi için yeni teknolojilerin geliştirilmesi ve kullanılması sayesinde 3B modeller yaygınlaşmıştır (Ulvi vd. 2020). 3B modeller, alanların geometrik temsilinin yanında, hesaplama, analiz kapasitesiyle farklı mekânsal detayları ve topolojik özellikleri sınıflandırıp birleştirebilirler. 3B modeller, navigasyon, turizm, kültürel miras, kentsel ve çevresel planlama gibi farklı uygulamalarda kullanılabilirler (Yakar vd. 2005; 2015). 3B kent modelleri, kentsel çevrenin geometrisinin küçük ölçekli 3B temsilidir ve birçok alana uygulama potansiyeli nedeniyle çok daha fazla ilgi görmektedir (Döllner vd. 2006; Biljecki vd. 2015; Yastıklı \& Çetin 2016).

Modellemede șehrin en temel unsurlarl; binalar, yollar, yeşil alanlar ve su alanlarıdır. Özellikle kent yapıları içerisinde binalar temel objeler olarak ele alınmakta ve daha çok binaya odaklanılmaktadır. Bu bağlamda kent yapıları hakkında 3B bilgiler edinerek bu bilgilerin dijital ortamda gerekli veri formatlarında kullanıma sunulması gerekmektedir (Erener \& Yakar, 2012; Kaya vd., 2021).

Kentler üzerinde yapılan uygulamalar ilk başta iki boyut üzerinden gerçekleştirilirken, gelişen bilgisayar teknolojileri, artan veri çeşitliliği ile beraber bu süreç zamanla üçüncü boyuta taşınmıştır. Mekânsal bilgilerin 3B görselleştirilmesiyle beraber mekânsal içeriği kavrama ve algılama aşaması daha da kolaylaşmaktadır (Ulvi \& Yakar 2014). Kentsel tasarım ve planlama çalışmalarında kullanılmak üzere 3B modeller elde etmek için kaliteli (yeterli doğrulukta ve görsel zenginlikte) ekonomik ve güncel verilere ihtiyaç vardır (Hamal vd. 2020). Günümüzde 3B modeller elde etmek için farklı yöntemler kullanılmaktadır. 3B kent modellerinin oluşturulması kapsamında en çok kullanılan iki yöntem LIDAR (Laser Imaging Detection and Ranging) ve fotogrametri yöntemidir.

LIDAR ölçme tekniği, öncelikle cansız doğa, bitki örtüsü ve insan yapımı yapılar (binalar) olmak üzere yer yüzeyindeki tüm özelliklere ilişkin ham verilerin toplanmasını sağlar (Kostrikov 2019). LIDAR farklı amaçlar için yoğun olarak kullanılan aktif bir sensör teknolojisidir. $\mathrm{Bu}$ teknoloji uzaydaki nesnelerin konumunu ve şeklini doğru bir şekilde ölçmek için en güvenilir teknolojilerden biridir (Balsa-Barreiro \& García, 2006; Heritage \& Large 2009; Balsa-Barreiro \& Fritsch 2018). LIDAR sistemlerinin üretilmesi ve yaygınlaşmasıyla beraber hem yerel hem de bölgesel ölçekte mekânın algılanması araştırıcılar için daha da kolaylaşmaktadır. Günümüzde lazer tarama yöntemleri, hızı ve yüksek doğruluğu sayesinde $3 \mathrm{~B}$ modelleme çalıșmalarında geniş bir kullanım alanına sahiptir (Sahin vd. 2012). 
Ullah vd. (2020) Akıllı kentlerin gelişiminde yapay zekanın rolünü araştırmıştır. Çalışmada, akıllı ulaşım sistemleri, siber güvenlik, enerjinin verimli kullanımı gibi konularda insansız hava araçlarının etkin bir şekilde kullanımı üzerinde durulmuştur. Akıllı bir kentte $5 \mathrm{G}$ ve $5 G$ üstü iletişim ile beraber, akıllı sağlık sisteminin hizmetlerini kesintisiz sağlamak ve geliştirmek için insansız hava araçlarının kullanımı önerilmiştir.

Vu ve Kaddoum (2017) Akıllı kentlerde atık yönetim uygulamaları üzerine çalışmıştır. $\mathrm{Bu}$ çalışmada tasarlanan model, atığın hacim verisini internet üzerinden algılamakta, ölçmekte ve ilgili merkeze iletmektedir. Çöp kutusunun coğrafi konumu ve seri numarası dahil olmak üzere toplanan veriler, regresyon, sınıflandırma ve grafik analizlerine tabi tutulmuştur. Sonuç olarak çöp kutularının konumları sınıflandırılarak atık durumu tahmin edebilir ve izlenebilir hale gelmiştir. $\mathrm{Bu}$ çalışmada tasarlanan model sayesinde atık toplama işlemi dinamik ve verimli bir şekilde yönetilebilecektir. Ayrıca uygulamada çöp kamyonunu verimli bir şekilde organize etmek için rotanın optimizasyonu otomatik olarak sağlanmaktadır.

Zeybek (2020) Kentsel alanlardaki enerji nakil hatlarının kestiriminde mobil lazer tarayıcıları kullanmıştır. Elde edilen nokta bulutu verileri istatistiksel yöntemler kullanılarak modellenmiștir. Üretilen nokta bulutları enerji nakil hatlarının 3B şekilde görselleștirme özelliğine sahiptir. Ancak gürültülü noktalar nedeniyle hassas verilerin üretiminde bazen zorluklarla karşılaşılabilmektedir. Çalışmada bu gibi problemlerin önüne geçmek amaciyla 2 temel aşama önerilmiştir. Birinci aşamada, nokta bulutu verilerinin voksel tabanl algoritmayla seyreltilmesi ve sınıflandırılmasıdır. İkinci aşama ise noktaların mesafe temelli algoritmayla gruplanarak nakil hatları için doğrusal olmayan modellerin kestirilmesidir. Kullanılan yöntemin verimliliği ve doğruluğu uygulama aşamasında araştırılmıştır. Önerilen yöntem ülkemizdeki enerji nakil hatları envanter verisinin toplanmasina katkı sağlayabilecektir. Ayrıca gerekli mühendislik çalışmalarının yapılmasında kaynak sarfiyatının önüne geçebilme potansiyeline sahiptir.

Mahdianpari vd. (2021) Yüksek çözünürlüklü uydu görüntüleri kullanarak akıllı kentler için çözümler önermiştir. Çalışmada; Kanada Newfoundland, St. John's City'deki sulak alanların haritalama ihtiyacının giderilmesi üzerine bir uygulama yapılmıștır. Bir kentsel alan içindeki beş farklı sulak alan sınıfını karakterize etmek için WorldView-4, GeoEye-1 ve LIDAR verilerinden yararlanılmış, ayrıca nesne tabanlı bir algoritma kullanılmıştır. Sonuç olarak yüksek çözünürlüklü görüntüler ve LIDAR kullanarak, \%91,12'lik bir doğrulukta sınıflandırılmış haritalar üretilmiştir. Ortaya çıkan sulak alan sınıflandırma haritası ve su akış haritası, sulak alanların şehrin peyzajına nasıl bağlandığının anlaşılmasına yardımcı olabilecektir. Ayrıca çalışma St. John Şehri için sulak alanla ilgili tam koruma ve etkili yönetim kararlarının alınmasını sağlayacaktır.

Dlodlo vd. (2016) Yapılan çalışmada internet faktörünün akıllı kentler üzerindeki rolünü araştırmışlardır. Çalıșmada kenti destekleyen hizmetler ve uygulamalar (turizm, sağlık, suç önleme ve toplum güvenliği vb.) değerlendirilmektedir. İnternetin entegrasyonu ile beraber akıllı kent uygulamalarında yeni yaklaşımlar önerilmektedir.

Nuaimi vd. (2015) Akıllı kentlerde büyük veri (big data) uygulamalarını değerlendirmişlerdir. Akıllı kentler ve büyük verilerin literatürdeki farklı tanımlarını tartışmışlar, akıllı kentlerde büyük veri uygulamalarının, zorluklarını, faydalarını ve gereksinimlerini araştırmışlardır. Bu araștırma, akıllı kentlerde büyük veriyi kullanmak için çeşitli firsatların varlığını ortaya koymakta; ancak bu firsatların iyi kullanılmasını sağlamak için ele alınması gereken birçok sorun ve zorluk olduğunu bildirmektedir.

Mohammed vd. (2014) Akıllı kentlerde insansız hava araçlarının kullanımı üzerine bir çalışma yapmıştır. İnsansız hava araçları, kentlerde, çevresel tehlikelerin izlenmesi, trafik yönetimi ve kirlilik izleme gibi birçok alanda geniş bir kullanıma sahiptir. Bu uygulamaların tamamı bir akıllı kentin gelişimine büyük katkılar sağlamaktadır. Ancak günümüzde güvenlik, mahremiyet ve etik olmayan kullanımlar gibi konular büyük endişe oluşturmaktadır. Çalışmada, akıllı kentlerde insansız hava araçlarının (IHA) uygulamalarının artıları ve eksileri tartışılmaktadır.

Jovanovi'c vd. (2020) Akıllı kent uygulamaları için sanal 3B kent modellerin üretilmesi üzerine çalıșmışlardır. Çalıșma alanı Sırbistan Novi Sad Üniversitesi Kampüs Alanı olarak belirlenmiştir. Çalışmada, havasal lazer tarama ölçümlerine dayalı sanal 3B kent modeli geliştirilmiştir. Çalışmada lazer tarama sistemlerinin 3B sanal kent modelleri geliștirmede ve bu gibi güncel uygulamalarda potansiyel kullanım senaryoları tartışılmaktadır.

$\mathrm{Bu}$ çalışmada, akıllı kent teknolojilerinin sürekli ihtiyacı olan kent elemanlarının 3B modellerinin, YLT yöntemi ile üretilmesi araştırılmıștır. Çalıșma alanı Mersin'in tarihi çeşmelerinden biri olan Süslü Çeşme olarak belirlenmiştir. Çeşmenin 3B modelinin oluşturulması aşamasında FARO marka FocusS 350 modelinde YLT kullanılmıștır. Uygulamanın veri toplama aşamasında 14 istasyon noktasından tarama işlemleri gerçekleştirilmiştir. Veri işleme aşamasında ise SCENE yazılımı kullanılmıștır. Taramalar sonucunda tarihi çeşmenin nokta bulutu elde edilmiştir. Yapılan birleştirme, düzenleme, temizleme ve renklendirme işlemlerinin ardından çeşmenin 3B modeli elde edilmiştir.

\section{2. ÇALIŞMA ALANI}

Kentler birçok fiziksel donatının bir araya gelmesinden oluşurlar. Kentlerdeki önemli kamusal alanlardan biri olan çeşmeler kentin kendine has kimliğini ve estetiğini sergilerken bazende önemli bir kentsel unsur olarak karşımıza çıkabilmektedir. Çeşmeler su sağlamasının yanında, özellikle kentsel alanlarda, trafikte hem araçlar hem de yayalar için yönlendirme işlevi de yapabilmektedir. Bir yolun ikiye bölündüğü ve şehir merkezlerine doğru devam ettiği bölümlerin başında çeşmeler yapılarak yol ayrımları estetik olarak vurgulanabilmektedir.

Büyük ve göz alıcı mimari yapılara ve tasarıma sahip çeşmeler ile tarihi çeşmeler daha fazla tanınmakta ve bu nedenle bulundukları çevreye adını verebilmektedir. Ayrıca su kaynaklarının tanınmasında kaynakların su 
kalitesi önemli bir yere sahiptir. Ülkemizdeki çoğu șehrin kendine özgü tarihini ve kültürel dokularını içinde barındırdığı tarihi kent çeşmeleri bulunmaktadır (Özer 2008).

Mersin'in Akdeniz İlçesi İhsaniye Mahallesinde konumlanan Süslü Çeşme Kuvayı Millîye (eski adı Hastane Caddesi) ve Havuzlar Caddesi arasinda yer almaktadır (Şekil 1).

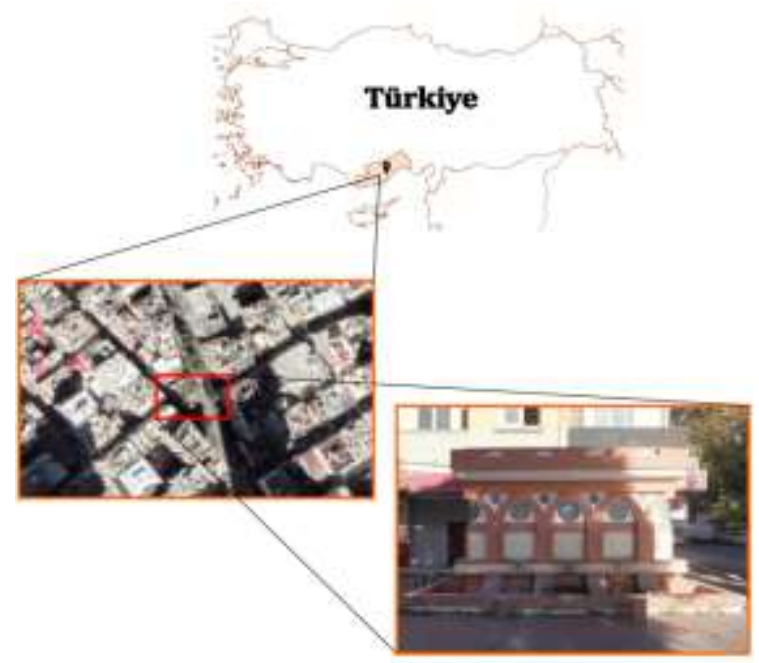

Şekil 1. Çalışma alanı

Süslü Çeşme 1930 yıllarında inşa edilmiştir. İnşa edildiği konum Mersin'in güney-kuzey gelișme aksı üzerindedir (Şekil 2).

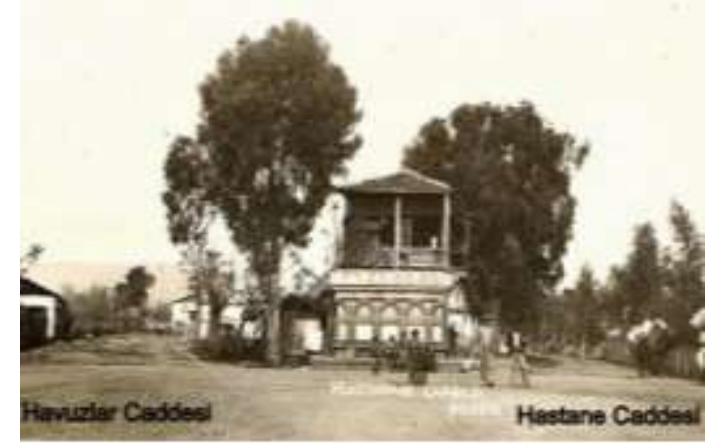

Şekil 2. Mersin Süslü Çeşme 1930 yılları (Pinterest 2021)

Süslü Çeșme yapısal olarak dikdörtgen prizma formundadır. Yapının üç yüzeyi çeşme dizaynında iken, kuzey yüzeyi düzdür. Çeşme 7 gözlü ve 9 su yalaklı olacak şekilde inşa edilmiştir. Tavan kısmı kemerli 10 niş ile betonarme olarak yapılmıştır. Çeşme yapısal olarak geleneksel mimarimiz ile modernizmin taşımaktadır (Everest \& Merzeci (2011).

Çeşmenin güney cephesi 3 , batı ve doğu cephesi 2 , güney-batı ve güney-doğu köşeleri ise 1'er tane olmak üzere sivri kemer görünümündedir. Bu sivri kemerlerin her birinde köşelerdekilerin haricinde musluklar yerleştirilmiştir. Çeşme çeşitli dönemlerde farklı renklerle boyanmıştır (Şekil 3).

Çeşme yıldız motifli alçı ve seramik bezemeler ile çinilerle süslenmiştir. Süslemeler sivri kemerlerin üst iç kısımlarında daire ve sekizgen formundadır. Kemer üst aralarında aynı formda daha küçük boyutta seramik kaplamalar bulunmaktadır. Çeşmenin musluk kesiminde ve kemer alt kısmında yıldız ve çiçekli bezemeler mevcuttur (Şekil 4). Seramik kaplamalı cepheleri ona "süslü" sıfatını kazandırmıștır.

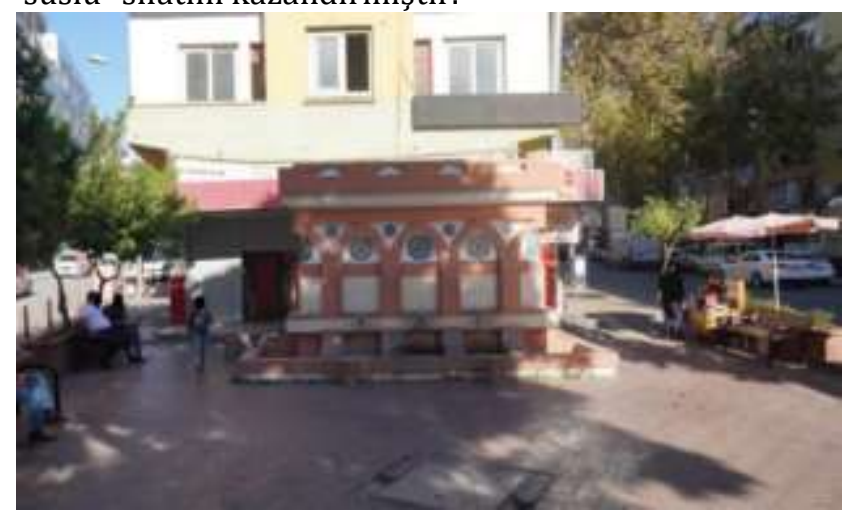

Şekil 3. Süslü Çeşme

Tarihsel süreçte kentin elektriğe kavuşmasından sonra Mersin'de temiz su arama çalışmaları hızlanmıştır. Günümüzdeki Asri Mezarlığın 150 metre kadar güneyinde sondaj çalışmaları başlamıştır. Ancak çıkarılan suyun içilemez olması nedeniyle çeşmeye su verilemediğinden Süslü çeşme ismi halk arasında Kuru Çeşme olarak adlandırılmaktadır (Kokulu 2013).

$\mathrm{Bu}$ eserin günümüzde şehir suyu bağlantısı vardır. Süslü Çeşme Mersin'in önemli bir kültür mirası olarak bilinmektedir.

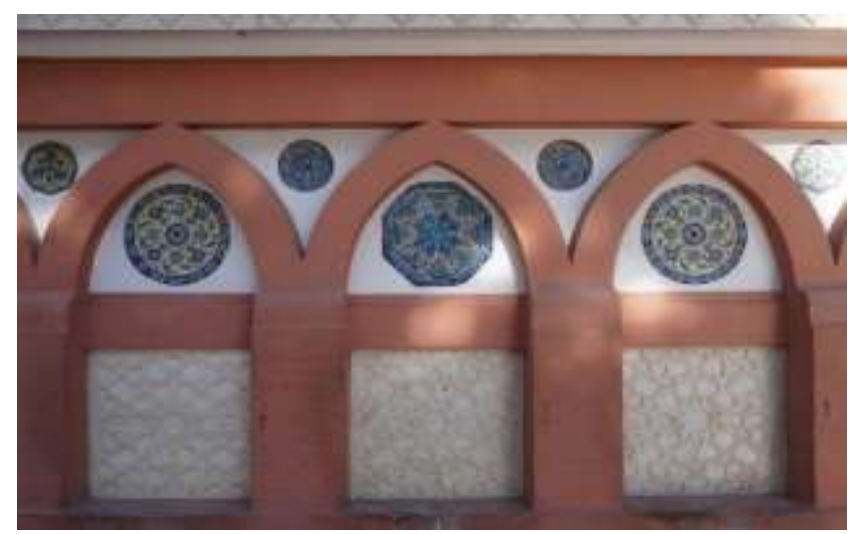

Şekil 4. Mersin Süslü Çeşme yakın görünümü

\section{YÖNTEM}

Son yıllarda pek çok alanda 3B coğrafi modelleme yöntemlerine ihtiyaç duyulmaktadır. Mekânın algılanmasında kullanılacak yaklașım erişilecek veri setine ve ihtiyaç duyulan 3B modelin özelliklerine göre değişmektedir.

LIDAR tekniği bu konuda kendisini uzun yıllardır kanıtlanmış ve yaygın olarak kullanılmakta olan bir teknolojidir (Keleş \& Aydın 2020). Bu teknoloji kısa sürelerde fiziksel verilerin hassas ve yoğun bir şekilde ölçülmesine olanak tanımaktadır. LIDAR yöntemi sayesinde objeyle herhangi bir temas olmadan doğrudan hassas ve otomatik bir șekilde 3B modeller üretilebilmektedir. LIDAR teknolojileri, mekânsal veri dışında herhangi bir veriye ihtiyaç duyulmaması ve verileri işlemenin prensipte otomatik olarak yapılması sayesinde diğer yöntemlerden öne çıkmaktadır (Zeybek 2021). Ayrıca LIDAR teknolojileri ölçümden hemen sonra dijital veri sağlayabilmektedir. Bütün bu sağladığı kolaylıklar farklı alanlarda LIDAR teknolojilerinin kullanımını arttırmıştır (Masaharu \& Hasegawa 2000). 
LIDAR yöntemi; madencilik uygulamaları, endüstriyel uygulamalar, kültürel mirasın korunması ve belgelenmesi, arkeoloji, afet izleme, kıyı uygulamaları, mimari ve bina ölçme, ulaşım ve altyapı gibi birçok uygulamada sıklıkla kullanılan bir yöntemdir (Oruç \& Öztürk 2021). LIDAR sistemlerinin en çok kullanıldığı bir diğer uygulama alanı ise kent objelerinin 3B modellenmesi ve bu modellerin içerdiği cadde, sokak gibi mekânlardır (Metin 2016).

LIDAR sensörü veri toplama için hava veya kara platformları üzerine monte edilebilir. LIDAR teknolojileri tarama için kullanılan platforma göre üç sınıfa ayrılmaktadır; bunlar havadan, karasal (yersel) ve mobil LIDAR sistemleridir. Üç tip LIDAR sistemi de akıllı kent projelerinin uygulanması ve kentsel alan araştırmaları sırasında veri toplamak için popüler ve güçlü araçlardır (Abellán vd. 2014). Lazer tarama sistemleri, belirli koşullar altında uygulama maliyetleri ve teknik performansları ile ilgili bazı dezavantajlara sahiptir. Havadan lazer tarama sistemleri ile detaylı bina cephelerine sahip 3B kentsel modeller elde edilemezken, mobil lazer tarama sistemleri (araç üstü ya da el tipi) için bazı alanlara erişim kısıtlanabilmektedir. Ayrıca, bu sistemler, çoğu gereksiz olan büyük miktarda veri ürettiğinden verinin işlenmesi daha da karmaşık hale gelebilir (Sahin vd. 2012). İstenilen doğruluk hassasiyeti, mekânın büyüklüğü, zaman, ekonomik durum, eldeki imkanlar ve diğer şartlar (trafik yoğunluğu, insan yoğunluğu hava şartları, erişilebilirlik) gibi etmenler doğrultusunda uygun tip lazer tarama sisteminin seçilmesi oldukça önemlidir.

3B kent modellerinin üretilmesi aşamasında; kent merkezlerinde, dar sokaklar, insan yoğunluğu ve trafik nedeniyle araçların bazı sokaklara erișimi kısıtlanabilmektedir. Bu gibi kısitlamalar, bu ortamlarda veri toplamayı daha zor hale getirmektedir (BalsaBarreiro \& Fritsch 2018). Bu kapsamda çalışma alanının kentin merkezi konumunda olması, dar sokaklarla çevrilmesi, sürekli ziyaretçi akını ve trafik gibi etmenlerden kaynaklı yol güzergahlarına kısıtlı erișim nedeniyle uygulama YLT kullanılarak gerçekleştirilmiştir. YLT kısa mesafelerde potansiyel olarak daha doğru ve ayrıntılı ölçümler sağlamaktadır (Hiremagalur vd. 2007; Abellán vd. 2014).

YLT yatay ve düşey olmak üzere her iki eksende dönebilen bir mekanizmaya sahiptir (Alptekin \& Yakar 2019; 2020). Bu mekanizma cihazın optik merkezinden yansıtıcı bir hedefin yüzeyine olan mesafeyi hesaplamak için elektromanyetik radyasyonun emisyon ve geri dönüş süresini kullanır (Baltsavias 1999; Abellán vd. 2014). Yersel lazer tarayıcılar, ölçüm prensiplerine göre genellikle time-of-flight (uçuş zamanlı mesafe belirleme) ve phase-shift (faz farkı) olmak üzere iki sınıfa ayrılır.

\subsection{Uçuş zamanlı mesafe belirleme (time of flight) yöntemi}

Tarayıcı, ünitesinden yüksek enerjili bir lazer ışığı üretir ve hedef objeye gönderilir. Ardından tarayıcının algılayıcı sensörü objeden geri dönen ışığı algılar (San José Alonso vd. 2011). Tarayıcı, gönderdiği her lazer ışınının gidiş ve dönüş süresini kaydeder. Ardından sensör tarafından işaretlenen objeler ile gönderilen ışın arasındaki mesafeyi ve yansıtma değerini ölçer (Meng vd.
2010; Polat 2020). Aradaki mesafe ıșığın hedefe gidiș ve dönüşündeki geçen süreye göre hesaplanır.

\subsection{Faz farkı yöntemi (phase shift) yöntemi}

Uygulamada kullanılan YLT faz farkı yöntemi prensibine göre ölçümlerini gerçekleştirmektedir. Bu çalışma prensibinde tarayıcının sensörü sürekli olarak orta şiddette periyodik bir sinyal yayar. Yayılan bu sinyal nesnenin yüzeyinden yansıdıktan sonra sensör tarafından algılanır, ardından giden ve gelen sinyalin faz değerleri karşılaştırılır (Çelik vd. 2020). Bu faz farkı analiz edilerek mesafeler hesaplanır (Şekil 5). Bu tür tarayıcılar, geniş görüş alanı, yüksek miktarda nokta, yüksek menzil ve yüksek tarama hızları sağlarlar. Bu tarayıcılar genellikle görünür dalga boylarını kullanır (Ulvi 2021).

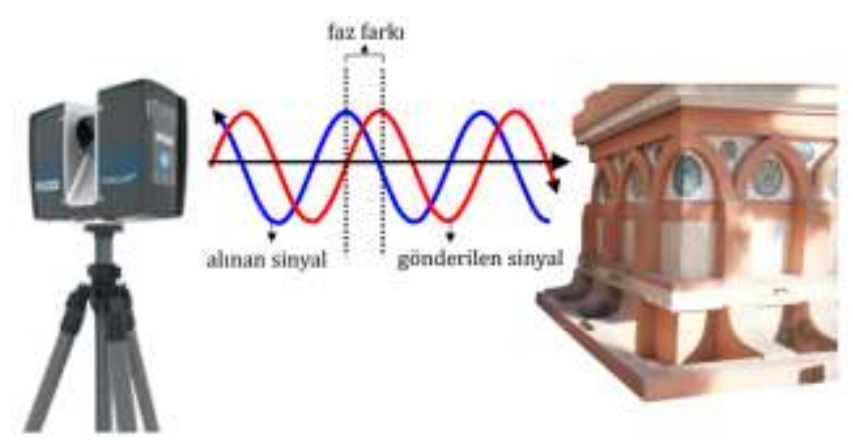

Şekil 5. Faz farkı yöntemi

3B görüntü oluşturmak için ışığın istenilen görüş alanındaki tüm noktalara yönlendirilmesi gereklidir. Kaydedilen veriler, ölçülen nesnenin konumunu tespit etmek ve yüzeyini anlamada yeterlidir (Liu 2008; Polat 2020). Lazer tarama sistemleri büyük miktarda ham veri toplar, bu veri "nokta bulutu" olarak adlandırılır. Tüm nokta bulutu bilinen bir koordinat sistemi referans alınarak ya da bölgesel koordinat sistemi kullanılarak aynı koordinat sistemine yönlendirilebilir. Nokta bulutundaki tüm noktalar $\mathrm{X}, \mathrm{Y}$ ve $\mathrm{Z}$ koordinatlarına sahiptir. Nokta bulutlarının birleştirilmesinde, noktaların renklendirilmesinde ve dokuların giydirilmesinde lazer tarayıcılara entegre dijital kameralardan yararlanılmaktadır. Farklı istasyonlardan bindirmeli olarak yapılan taramalardan elde edilen veriler çeşitli yazılımlar sayesinde işlenmekte ve 3B modeller elde edilmektedir. Bu çalışmada FARO marka YLT kullanılmıștır (Şekil 6).

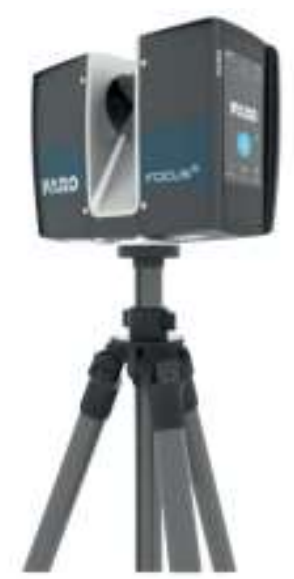

Şekil 6. FARO marka FocusS 350 model yersel lazer tarayıcı (Faro 2021) 
FARO kolay taşınabilir olma özelliğinin yanında hem iç hem de diş mekânlarda artırılmış mesafe ve açısal hassasiyeti ile doğruluğu yüksek taramalar gerçekleştirebilir. FARO, mühendislik, inşaat, mimari, ürün tasarımı, kamu güvenliği ve adli tıp gibi alanlardaki tüm uygulamalar için rahatlıkla kullanılabilir. Geniş dokunmatik ekranı ve kullanışlı arayüzü tarayıcının kontrolünü oldukça kolaylaştırmaktadır. Ayrıca gerçek zamanda yerinde bir mobil cihaza ya da bilgisayara doğrudan bağlantı kurarak 3D tarama verisinin kablosuz aktarılmasını ve işlenmesini desteklemektedir (Echosurveying 2021). Kullanılan YLT' nin teknik özellikleri Tablo 1'de vermiştir.

Tablo 1. Kullanılan yersel lazer tarayıcının teknik özellikleri (Faro 2021)

\begin{tabular}{ll}
\hline Öznitelik & Değer \\
\hline Boyut & $230^{*} 183^{*} 100 \mathrm{~mm}$ \\
Tararlı̀ıcı kontrolü & $4,2 \mathrm{~kg}$ \\
Batarya süresi & Dokunmatik \\
Tarama mesafesi & 4,5 saat \\
Hassasiyet & $0,6-50 \mathrm{~m}$ \\
Çözünürlük & $\pm 1 \mathrm{~mm}$ \\
Görüş alanı (dikey, yatay) & $165 \mathrm{mp}$ \\
Azami dikey tarama hızı & $300^{\circ}, 360^{\circ}$ \\
Veri Depolama & $97 \mathrm{~Hz}$ \\
Pusula & SD, SDHC, SDXC, 32GB \\
HDR Fotoğraf Kaydı & Elektronik \\
Ölçüm Hızı & $2 x / 3 \mathrm{x} / 5 \mathrm{x}$ \\
\hline
\end{tabular}

\section{UYGULAMA}

\subsection{Veri toplama}

YLT istasyonlarının sayısı ve konumu; mekânın topoğrafyasına, bina yüksekliği ile cadde genişliği arasındaki ilişkiye, araç ve insanların varlığı ve nesnenin karmaşıklığı gibi faktörlere bağlıdır. Bu nedenle lazer tarama öncesinde en verimli performansa ulaşmak için istasyonların konumları ve oturum sayları planlanmalıdır. Her tarama istasyonunun sayısı ve konumu, her bir tarama istasyonundan elde edilen görüş alanından etkilenmektedir. Taramanın doğruluğu tarama istasyonlarının sayısı ve istasyonların konumları ile bağlantılıdır. Tarama çözünürlüğü kavramı nokta bulutundaki noktaların aralarındaki boșluklar ile ilișkilidir. Tarama çözünürlüğü arttırıldıkça nokta bulutundaki noktalar arası boșluklar azalmakta, dolayısıyla taranan nokta sayısı artmaktadır. Diğer bir deyişle yüzey daha çok nokta ile temsil edilmektedir. Bu sayede 3B modeldeki ayrıntı seviyesi artmaktadır. Ancak bununla beraber tarama dosyasının boyutu da oldukça artmaktadir.

Uygulamada bazı bölgelere kısıtlı erişim nedeniyle cepheler için sınırlı görüş saptandığından başlangıçta belirlenen istasyonların sayısı arttırılmıștır. 14 YLT istasyonu, tüm cepheleri tamamen kapsayacak şekilde çeşmenin etrafına mekânsal olarak iyi bir şekilde dağıtılmıştır. Tarama işlemine başlamadan önce cihaz planlanan tarama istasyonlarına kurulmuş ve ölçüm için gerekli parametreler cihaza girilmiştir (Şekil 7).

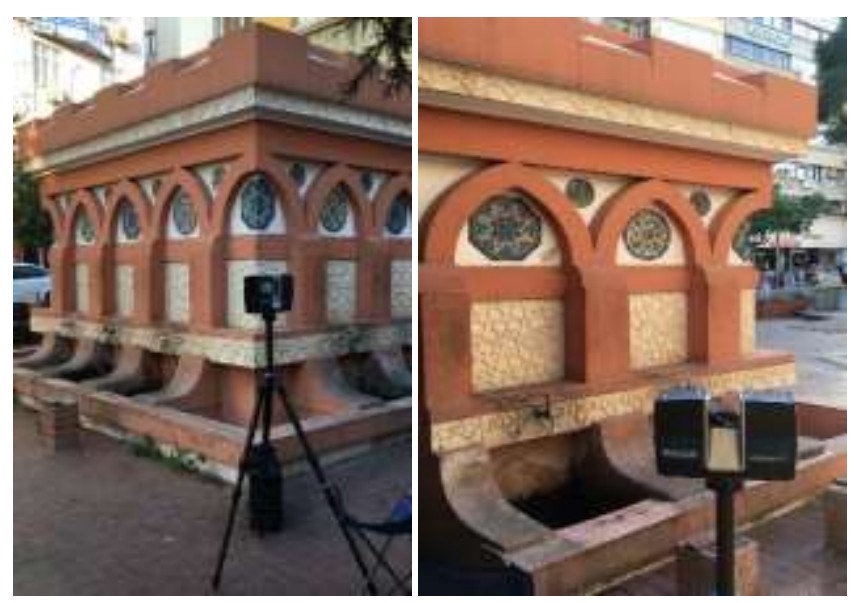

Şekil 7. YLT ile veri toplama aşaması

Tarama çözünürlüğü her istasyon için; ölçüm modu ayarı eşit ağırlıklı ölçüm, renkler açık, tarama çözünürlüğü $1 / 4$, tarama kalitesi $3 x$, tarama mesafesi ise 20 m altında seçilerek taramaya bașlanmıștır. Tarama süresi bütün istasyonlarda 9 dakika 40 saniyedir. Tablo 2'de tarama parametrelerinin sayısal değerleri gösterilmiştir.

Tablo 2. Tarama parametreleri

\begin{tabular}{lcccc}
\hline Çözünürlük & Süre & Tarama Boyutu & Mesafe & Kalite \\
$1 / 4$ & $9 \mathrm{dk} 40 \mathrm{sn}$ & $10240 \times 4267 \mathrm{Pn}$ & $<20$ & $3 \mathrm{x}$ \\
\hline
\end{tabular}

YLT sensörünün menzilindeki objelerden etkilenen tüm alan göz önüne alındığında, 14 istasyondan toplamda 4 milyondan fazla nokta içeren kapsamlı bir nokta bulutu elde edilmiștir. Tarama esnasında hedef noktalar (targetler) ve yer kontrol noktaları kullanılmamıştır. Veri işleme aşamasında tarama oturumlarının birleştirilmesi dijital ortamda rastgele otomatik noktalar (cloud to cloud) yardımıla gerçekleştirilmiştir.

\subsection{Veri işleme}

Taramalar sonucunda elde edilen verilerin işlenmesi, düzenlenmesi ve birleştirilmesi için çeşitli yazılımlar geliştirilmiştir. Piyasada çeşitli şirketlerin geliștirdiği birçok yazılım mevcuttur. Uygulamada sınıflandırma doğruluğu, hızlı çalışması ve kullanışlı ara yüzü nedeniyle SCENE yazılımı kullanılmıștır. SCENE yazılımı ile kullanıcılar, gerçek dünyadaki objelerin ve ortamların 3B görselleștirmelerini oluşturabilirler. Ayrıca bu verileri çeşitli formatlarda dışa aktarabilir.

Tüm istasyonlardan elde edilen ham veri boyutu toplamda $3.45 \mathrm{~Gb}^{\prime}$ dır. Başlangıçta, SCENE' de bir proje adı ve klasör oluşturulmuştur. Daha sonra ham veri 
setleri SCENE' e aktarılmıștır. Bu işlem yapılırken verinin sınırlarını üç eksende, varsa tarama açısı, yoğunluk ve lazer ıșınının geri dönüş bildirimi gibi diğer yardımcı bilgileri analiz edilmektedir. Daha sağlıklı bir modelleme elde etmek için öncelikle nokta bulutunun sinıflandırılması yapılmalıdır. Ancak tek bir yapı üzerinde çalışıldığı için bu uygulamada sınıflandırma işlemi yapılmamıştır. Her bir istasyonlardan elde edilen nokta bulut verileri birleştirildikten sonra noktaların temizlenmesi aşamasına geçilmiştir (Şekil 8).

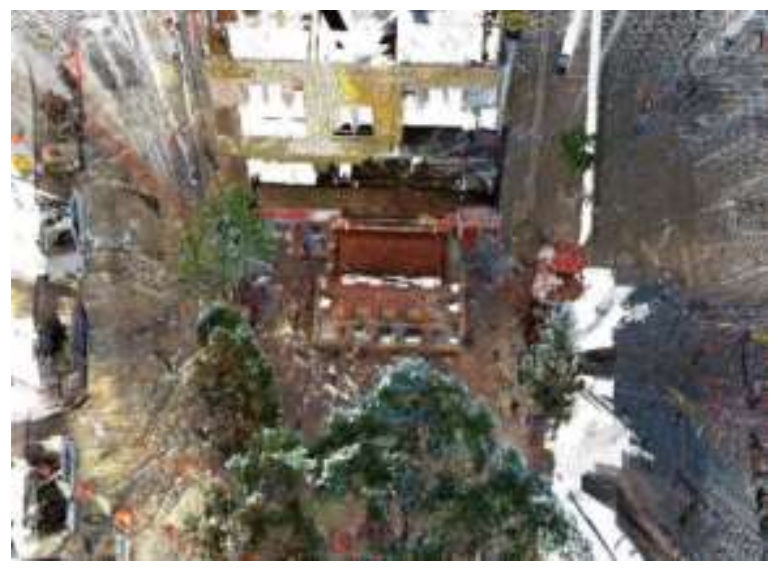

Şekil 8. Nokta bulutu

Lazer tarayıcı sensörü çevreye ait diğer tüm verileri de kaydettiğinden ilgisiz ve gereksiz noktalar temizlenmiştir. Son olarak renklendirilme işlemi yapılmış ve 3B modelleme işlemi tamamlanmıştır (Şekil 9 ve 10$)$.

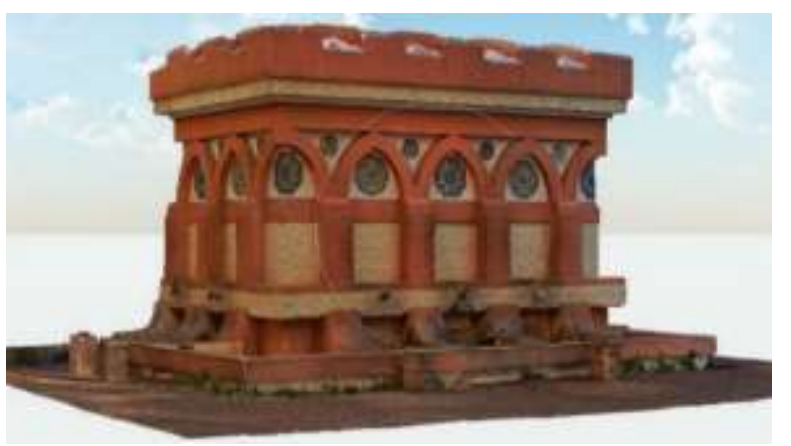

Şekil 9. Çeşmenin 3B modeli (güney, batı)

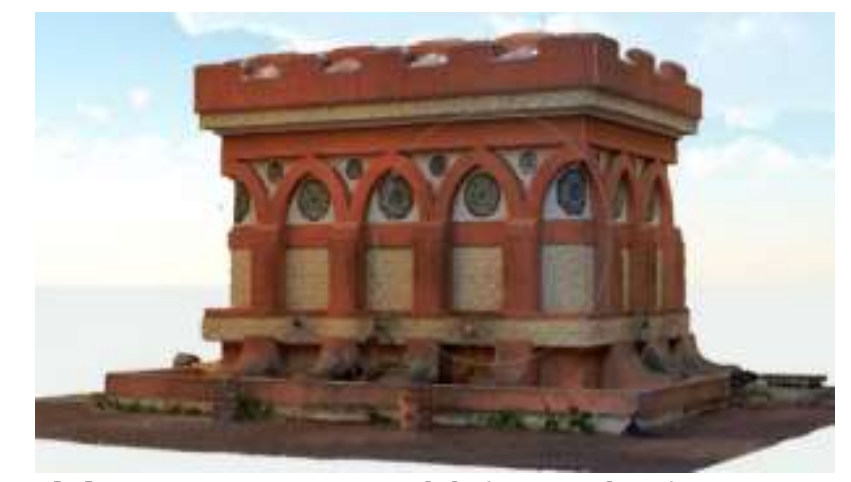

Şekil 10. Çeşmenin 3B modeli (güney, doğu)

Veri işleme; Microsoft Windows 10 işletim sistemi, Intel Xeon e5-2620 v4 $2.10 \mathrm{GHz}$ işlemci, $128 \mathrm{~GB}$ bellek kapasitesi, Nvidia Quadro m4000 8GB ekran kartı, teknik özelliklerine sahip bir bilgisayarda gerçekleştirilmiştir.

\section{SONUÇLAR}

3B akıllı kent modelleri, akıllı kentler, navigasyon ve görselleştirme, çevre koruma, ulaşım, turizm, kent planlama, kamu güvenliği ve şehir hizmetleri, planlama, endüstriyel, sosyal ve ticari faaliyetler gibi farklı uygulamalar için yaygın olarak kullanılmaktadır.

Şehir merkezlerinde (çarşılarda), dar sokaklar, sürekli devam eden ziyaretçi akını ve trafik gibi kısıtlanan erişimler nedeniyle araçların bazı sokaklara erişimi kısıtlanabilmektedir. $\mathrm{Bu}$ gibi kısıtlamalar, mekânlarda veri toplamayı daha da zorlaştırmaktadır. $\mathrm{Bu}$ yüzden kullanılacak yöntemin seçiminde, modellenecek nesnenin bulunduğu ortamın dikkate alınması büyük rol oynamaktadır.

Çok sayıda çalışma, kentsel alanlarda fotogrametrik tekniklere ve lazer taramaya dayalı 3B modellemeye odaklanmıștır. Hatta her iki yönteminde bir arada kullanıldığı hibrit yöntemler önerilmiştir. Ancak şimdiye kadar, yüksek doğrulukta ve estetik 3B modeller oluşturmak için hangi metodolojinin en uygun olduğu konusunda hala bir tartışma vardır. YLT yöntemi kentlerin 3B modellenmesinde sağladı̆̆ kolaylıklar sayesinde sıklıkla kullanılan bir yöntem haline gelmiştir. Çok kısa sürelerde ve yeterli hassasiyetlerde yapıların 3B modelleri kolayca elde edilmektedir.

Uygulamada tarama çözünürlüğü $1 / 4$, tarama kalitesi 3x, tarama mesafesi $20 \mathrm{~m}$ altında seçilmiştir. Tarama sırasında herhangi bir kontrol noktası kullanılmamış 14 istasyon noktasından elde edilen nokta bulutlarının birleştirilmesi farklı istasyonlardan bindirmeli olarak yapilan taramalardan otomatik olarak elde edilen ortak noktalar yardımıyla gerçekleştirilmiştir. Ayrıca çalışmada jeoreferanslama yapılmamış elde edilen nokta verilerinin koordinatları tarayıcının kendi (lokal) koordinat sisteminde otomatik olarak tanımlanmıștır. Oturumlardan elde edilen nokta bulutlarının birleştirilmesi ortalama $\pm 3,9 \mathrm{~mm}$ hata ile tamamlanmıștır. Gereksiz noktaların silme işlemi her istasyon için de gerçekleştirilmiştir. Son olarak nokta bulutu renklendirilmiștir. Otomatik üretilen noktalar sayesinde tüm yapı 71 milyondan fazla nokta ile temsil edilmektedir. Ortaya çıkan 3B sanal model doğru, ayrıntılı ve görsel olarak estetik nitelik taşımaktadır. Burada elde edilen 3B sonuç modeli, 3B kent modellerinde rahatlıkla kullanılabilir.

Üretilen 3B modelin doğruluğu, tarama öncesi seçilen tarama hassasiyeti ve oturumların birleștirilme hatası ile doğrudan bağlantılıdır. Taramada kullanılan tarayıcıların teknik özelliklerinin yanında taranacak objenin karmaşıklığı, tarama istasyonlarının konumları ve sayısı, tarama süresi, çözünürlük, menzil, tarama açısı, veri işleme aşamasında kullanılan yazılım gibi faktörler çıktı ürününün hassasiyetini etkilemektedir. Ayrıca uygun tip tarayıcının seçilmesi maliyet açısından kaynak sarfiyatının önüne geçilmesini sağlayacaktır.

YLT yapıların cephelerinin modellenmesinde oldukça iyi işler çıkarmasına rağmen çatılarda eksik kalmaktadır. Bu yüzden yüksek katlı yapıların çatı detayı için YLT önerilmemektedir. Ayrıca yüzeylere dik olan ölçümler daha yüksek seviyelerde doğruluk göstermektedir. YLT yöntemi kısa bir süre içinde nesne yüzeyi hakkında bir görselleştirme sağlayabilir. YLT bu 
esnekliği sayesinde kullanışlıdır. Yapılan çalışmada YLT teknolojisinin kullanılan diğer yöntemlerden daha üstün ve daha esnek bir yöntem olduğu tespit edilmiștir. Küçük sayılabilecek ölçekli yapıları 3B modellemede ve akıllı kent uygulamalarında kullanmada YLT teknolojileri alternatif bir yöntem olarak kullanılabilir.

\section{Yazarların Katkısı}

Yazarlar bu araştırma makalesine eşit katkı sunmuşlardır.

\section{Çıkar Çatışması Beyanı}

Yazarlar arasında herhangi bir çıkar çatışması bulunmamaktadır.

\section{Araştırma ve Yayın Etiği Beyanı}

Yapılan çalışmada araştırma ve yayın etiğine uyulmuştur.

\section{KAYNAKÇA}

Abellán A, Oppikofer T, Jaboyedoff M, Rosser N J, Lim M \& Lato M J (2014). Terrestrial Laser Scanning of Rock Slope İnstabilities. Earth Surface Processes and Landforms, 39(1), 80-97.

Al Nuaimi E, Al Neyadi H, Mohamed N \& Al-Jaroodi J (2015). Applications of big data to smart cities.Journal of Internet Services and Applications, 6(1), 1-15.

Alptekin A \& Yakar M (2020). Kaya Bloklarının 3B Nokta Bulutunun Yersel Lazer Tarayıcı Kullanarak Elde Edilmesi. Turkey Lidar Journal, 2(1), 1-4.

Alptekin A, Çelik M Ö, Doğan Y \& Yakar M (2019). Mapping of a Rockfall Site With an Unmanned Aerial Vehicle. Mersin Photogrammetry Journal, 1(1), 1216.

Alonso J S J, Rubio J M, Martin J F \& Fernandez J G (2011). Comparing Time of Flight and Phase Shift. The Survey of the Royal Pantheon in the Basilica of San Isidoro(Leon). In procs. of ISPRS Workshop'3D ARCH.

Aslan M M \& Bulut Y (2019). Akıllı Kent Uygulamalarının Kentsel Güvenlik Açısından Önemi. Assam Uluslararası Hakemli Dergi, 52-60.

Balsa-Barreiro J \& Fritsch D (2018). Generation of Visually Aesthetic and Detailed 3D Models of Historical Cities by Using Laser Scanning and Digital Photogrammetry. Digital Applications in Archaeology and Cultural Heritage, 8, 57-64.

Baltsavias E P (1999). Airborne Laser Scanning: Basic Relations and Formulas. ISPRS Journal of Photogrammetry and Remote sensing, 54(2-3), 199-214.
Barreiro J B \& García J L L (2006). La tecnología LiDAR: una visión general. Topografía y Cartografía: Revista del Ilustre Colegio Oficial de Ingenieros Técnicos en Topografía, 23(135), 28-33.

Biljecki F, Stoter J, Ledoux H, Zlatanova S \& Çöltekin A (2015). Applications of 3D City Models: State of The Art Review, ISPRS Int. J. Geo-Inform., 4, 2842-2889.

Çelik M Ö, Hamal S N G \& Yakar İ (2020). Yersel Lazer Tarama (YLT) Yönteminin Kültürel Mirasın Dokümantasyonunda Kullanımı: Alman Çeşmesi Örneği. Turkey Lidar Journal, 2(1), 15-22.

Dlodlo N, Gcaba 0 \& Smith A (2016). Internet of things technologies in smart cities. In 2016 IST-Africa Week Conference, 1-7.

Döllner J, Baumann K \& Buchholz H (2006). Virtual 3D city models as foundation of complex urban information spaces 107-112.

Echosurveying (2021). https://echosurveying.com/3dlaser-scanner/faro-focus-s350-laser-canner(Erișim Tarihi: 01.11.2021)

Ernst F, Şenol H İ, Akdağ S \& Barutcuoglu Ö (2021). Virtual Reality for City Planning. Harran Üniversitesi Mühendislik Dergisi, 6(3), 150-160. DOI: $10.46578 /$ humder.941015

Everest A \& Merzeci A M (2011). Mersin'in Çeșmeleri ve Anıt Ağaçları. Mersin Üniversitesi Tıp Fakültesi Lokman Hekim Tıp Tarihi ve Folklorik Tıp Dergisi, 39-39.

Faro(2021).https://www.faro.com/en/Products/Hard ware/Focus-Laser-Scanners (Erişim Tarihi: 01.11.2021)

Hamal S N G, Binnaz S \& Ulvi A (2020). Using of Hybrid Data Acquisition Techniques for Cultural Heritage a Case Study of Pompeiopolis. Türkiye İnsansız Hava Araçları Dergisi, 2(2), 55-60.

Heritage G \& Large A (2009). Laser Scanning for the Environmental Sciences.

Hiremagalur J, Yen K S, Akin K, Bui T, Lasky T A, \& Ravani B (2007). Creating Standards and Specifications for the Use of Laser Scanning in Caltrans Projects (No. CA07-0964).

Jovanović D, Milovanov S, Ruskovski I, Govedarica M, Sladić D, Radulović A \& Pajić V (2020). Building virtual 3D city model for Smart Cities applications: A case study on campus area of the University of Novi Sad. ISPRS International Journal of GeoInformation, 9(8), 476.

Kaya Y, Şenol H İ \& Polat N (2021). Three-dimensional modeling and drawings of stone column motifs in Harran Ruins. Mersin Photogrammetry Journal, 3(2), 48-52 . DOI: 10.53093/mephoj.1012937 
Keleş M D \& Aydın C C (2020) Mobil Lidar Verisi ile Kent Ölçeğinde Cadde Bazlı Envanter Çalışması ve Coğrafi Sistemleri Entegrasyonu-Ankara Örneği. Geomatik, 5(3), 193-200.

Kokulu V (2013). İçel Sanat Kulübü 2013-198 Sayılı Aylık Bülteni.

Kostrikov S V (2019). Urban Remote Sensing With Lidar For The Smart City Concept İmplementation. Вісник Харківського національного університету імені ВН Каразіна, серія" Геологія. Географія. Екологія", 50.

Liu X (2008). Airborne LiDAR for DEM Generation: Some Critical İssues. Progress in Physical Geography, 32(1), 31-49.

Mahdianpari M, Granger J E, Mohammadimanesh F, Warren S, Puestow T, Salehi B \& Brisco B (2021). Smart solutions for smart cities: Urban wetland mapping using very-high resolution satellite imagery and airborne LiDAR data in the City of St. John's, NL, Canada. Journal of Environmental Management, 280.

Masaharu H \& Hasegawa H (2000). Three-Dimensional City Modeling From Laser Scanner Data By Extracting Building Polygons Using Region Segmentation Method. International Archives of Photogrammetry and Remote Sensing, 33(B3/1; PART 3), 556-562.

Meng X, Currit N \& Zhao K (2010). Ground Filtering Algorithms for Airborne Lidar Data: A Review of Critical İssues. Remote Sensing, 2(12), 833-860.

Metin A (2016). Üç Boyutlu Kent Modellerinde Ayrıntı Düzeyi Kavramı İnce Minareli Medrese (Konya) Örneği. Master's Thesis, Necmettin Erbakan Üniversitesi Fen Bilimleri Enstitüsü.

Mohammed F, Idries A, Mohamed N, Al-Jaroodi J \& Jawhar I (2014). UAVs for smart cities: Opportunities and challenges. In 2014 International Conference on Unmanned Aircraft Systems, 267273.

Oruç M E \& Öztürk İ L (2021). Usability of Terrestrial Laser Technique in Forest Management Planning. Turkey Lidar Journal, 3(1), 17-24.

Özer S (2008). Geçmişten Günümüze Kent-Çevre ilişkisi İçinde Çeşmeler. Sanat Dergisi, (13), 129-134.

Özerbil T, Gökten E, Önder M, Selçuk O, Sarilar N Ç, Tekgül A \& Tütüneken A (2014). Konya Büyükşehir Belediyesi Eğik (Oblique) Görüntü Alımı, 3 Boyutlu Kent Modeli ve 3 Boyutlu Kent Rehberi Projesi. V. Uzaktan Algılama ve Coğrafi Bilgi Sistemleri Sempozyumu, 14-17.
Pinterest (2021). https://tr.pinterest.com/pin/4766779417862628 97 (Erişim Tarihi: 01.11.2021)

Polat N (2020). LIDAR Derived 3d City Modelling. The International Archives of Photogrammetry, Remote Sensing and Spatial Information Sciences, 44, 339342.

Sahin C, Alkis A, Ergun B, Kulur S, Batuk F \& Kilic A (2012). Producing 3D City Model With The Combined Photogrammetric and Laser Scanner Data in The Example of Taksim Cumhuriyet Square. Optics and Lasers in Engineering, 50(12), 1844-1853.

Şenol H İ, Pola N, Kaya Y, Memduhoğlu A \& Ulukavak M (2021). Digital documentation of ancient stone carving in Şuayip City. Mersin Photogrammetry Journal, 3(1), 10-14. DOI: 10.53093/mephoj.899157

Su K, Li J \& Fu H (2011). Smart City and The Applications. In 2011 İnternational Conference on Electronics, Communications and Control (ICECC), 1028-1031.

Ullah, Z, Al-Turjman F, Mostarda L \& Gagliardi R (2020). Applications of artificial intelligence and machine learning in smart cities. Computer Communications, 154, 313-323.

Ulvi A (2021). Documentation, Three-Dimensional (3D) Modelling and visualization of cultural heritage by using Unmanned Aerial Vehicle (UAV) photogrammetry and terrestrial laser scanners. International Journal of Remote Sensing, 42(6), 1994-2021.

Ulvi A \& Yakar M (2014). Yersel Lazer Tarama Tekniği Kullanarak Kizkalesi'nin Nokta Bulutunun Elde Edilmesi ve Lazer Tarama Noktalarının Hassasiyet Araştırması. Harita Teknolojileri Elektronik Dergisi, 6(1), 25-36. Retrieved from https://dergipark.org.tr/tr/pub/hartek/issue/758 9/99627

Vu D D \& Kaddoum G (2017). A waste city management system for smart cities applications. In 2017 Advances in Wireless and Optical Communications, 225-229.

Yakar M, Yıldız F \& Yılmaz H M (2005). Tarihi Ve Kültürel Miraslarin Belgelenmesinde Jeodezi Fotogrametri Mühendislerinin Rolü. TMMOB Harita ve Kadastro Mühendisleri Odası, 10.

Yakar M, Yılmaz H M \& Mutluoğlu H M (2009). Hacim Hesaplamalarında Laser Tarama ve Yersel Fotogrametrinin Kullanılması, TMMOB Harita ve Kadastro Mühendisleri Odası 12. Türkiye Harita Bilimsel ve Teknik Kurultayı, Ankara

Yakar M, Yilmaz H M \& Mutluoglu O (2010). Comparative Evaluation of Excavation Volume by TLS and Total 
Topographic Station Based Methods. Lasers in Engineering 19 (5-6), 331-345

Yakar M, Orhan O, Ulvi A, Yiğit A Y \& Yüzer M M (2015). Sahip Ata Külliyesi Rölöve Örneği. TMMOB Harita ve Kadastro Mühendisleri Odası, 10.

Yastıklı N \& Çetin Z (2016). Hava Lidar Verileri ile 3b Bina Modellerinin Otomatik Üretimi.

Yllmaz H M \& Yakar M (2008). Computing of Volume of Excavation Areas by Digital Close Range Photogrammetry. Arabian Journal for Science and Engineering 33 (1A), 63-79.

Yılmaz H M, Mutluoğlu Ö, Ulvi A, Yaman A \& Bilgilioğlu S S (2018). İnsansız Hava Aracı ile Ortofoto Üretimi ve Aksaray Kampüsü Örneği. Geomatik Dergisi. 3(2), 129-136.
Yılmaz H M, Yakar M, Mutluoglu O, Kavurmaci M M \& Yurt $\mathrm{K}$ (2012). Monitoring of soil erosion in Cappadocia region (SelimeAksaray-Turkey). Environ Earth Sci, 66, 75-81.

Erener A \& Yakar M (2012). Monitoring Coastline Change Using Remote Sensing and GIS Technologies. Lecture Notes in Information Technology, 30, 310314

Zeybek M (2020). Mobil LiDAR Nokta Bulutlarından Enerji Nakil Hatlarının Doğrusal Olmayan Modellerle Kestirimi. Turkey Lidar Journal, 2(2), 55-63.

Zeybek M (2021). Indoor Mapping and Positioning Applications of Hand-Held LiDAR Simultaneous Localization and Mapping (SLAM) Systems. Turkey Lidar Journal, 3(1), 7-16. 